\title{
A Case Presentation of Sarcoidosis Larynx
}

\author{
Pankaj Srivastva ${ }^{1 *}$, Mudit Mishra $^{2}$, Udita Deewan ${ }^{3}$ and Rohit Mehrotra ${ }^{4}$ \\ ${ }^{1}$ Director, Pankaj ENT Hospital, India \\ ${ }^{2}$ Consultant, Pankaj ENT Hospital, India \\ ${ }^{3}$ Director, Deewan Pathology, India
}

${ }^{4}$ Professor, GSVM Medical College, India

Submission: November 25, 2017; Published: December 06, 2017

*Corresponding author: Pankaj Srivastava, Pankaj ENT Hospital, 56-C Singar Nagar, Alambagh, Lucknow, India, Tel: 9984477770 ; Email: drpankajsrivastava@rediffmail.com

Abstract

Sarcoidosis is a multisystem disease, which rarely involves the larynx. Which is mostly limited to involvement of supraglottis-epiglottis, Aryepiglottic folds and false vocal cords. Diagnosis is by exclusion of other granulomatous infection and diseases, and histopathological confirmation. In this case report patient presented with change in voice, snoring. Diagnosis was made after excluding other differential diagnosis, confirmed by histopathology.

\section{Introduction}

Sarcoidosis is a multisystem disease of unknown aetiology, usually affecting the respiratory tract and other organs, and is characterized by the formation of nonnecrotizing epithelioid granulomas [1]. Incidence rate in US population is 10 people per 100,000 per year [2]. In india reported prevalence of sarcoidosis is 10-12 cases $/ 100,000$ new registration annually at a respiratory unit at Kolkata and 61.2/100,000 new cases registered in respiratory unit of the Vallabhbhai Patel Chest institute (VPCI), Delhi [3].

The central part of a granuloma is composed of macrophages, modified macrophages, epithelioid cells and giant cells, with scattered, predominately CD4+ T, lymphocytes between them [4]. Caseous necrosis is absent, while central necrosis, as a granular acidophilic focus without nuclear detritus, may be found [5]. It rarely involves larynx as extra pulmonary sites. Common presentation for laryngeal sarcoidosis are dysphonia, dysphagia, and dry cough, rarely can it cause total laryngeal obstruction leading to stridor [6]. We are presenting a case report of a patient who presented to us with complaint of change of voice, snoring and frequent arousal from sleep.

\section{Case Description}

A 25 year old female was referred by chest physician with complaints of change in voice and snoring and frequent arousal from sleep in night for 1 year. Patient was not having any complaint of fever, generalized weakness, palpable swelling in neck. Patient's general profile was height $161 \mathrm{~cm}$, weight $39 \mathrm{~kg}$, BMI- $15 \mathrm{~kg} / \mathrm{m}^{2}$. For these complains polysomnography and CECT chest were done by chest physician. AHI index was 14.5 , with average heart during sleep of 71 , highest heart rate during sleep of 173 , average $O_{2}$ saturation while in Non-REM- 98\%, and approximate minimum value of $\mathrm{O}_{2} 87 \%$, desaturation index 2.1, average heart rate during sleep 71 BPM, and highest heart rate during sleep of 173 BPM. CECT chest showed centrilobular nodules in right upper lobe, mainly in anterior and apical segment, and associated right hilar lymphadenopathy. After receiving the patient, endoscopic examination of larynx was done, which showed $u / l$ thickening of uvula left side, thickening of epiglottis turning to turban shape, aryepiglottic fold, and false vocal cords, both the true vocal cords were mobile, diagnostic nasal endoscopy was insignificant. CECT neck and upper mediastinum done was suggestive of prominent faucial tonsil, thick uvula and epiglottis, B/L aryepiglottic fold and false vocal cords. On the basis of clinical picture differential diagnosis of tuberculosis, amyloidosis and sarcoidosis were made. Biopsy was taken from uvula being very accessible for biopsy (Figures 1-3).

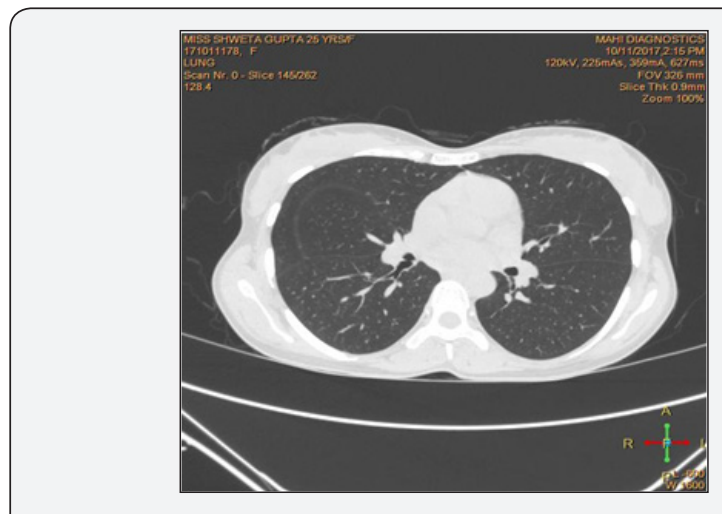

Figure 1: CT FILM showing Hilar Lymphadenopathy 


\section{Global Journal of Otolaryngology}

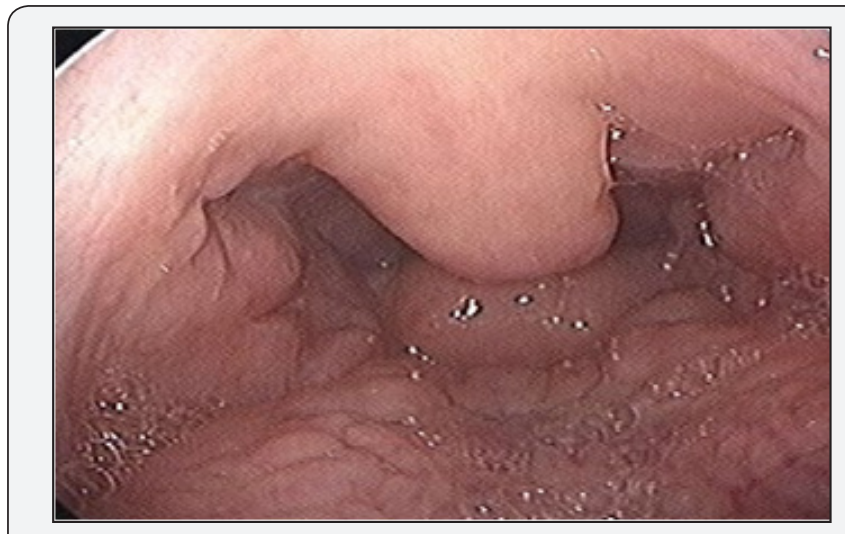

Figure 2: Endoscopic picture showing edematous uvula.

CT Film Showing Hilar Lymphadenopathy

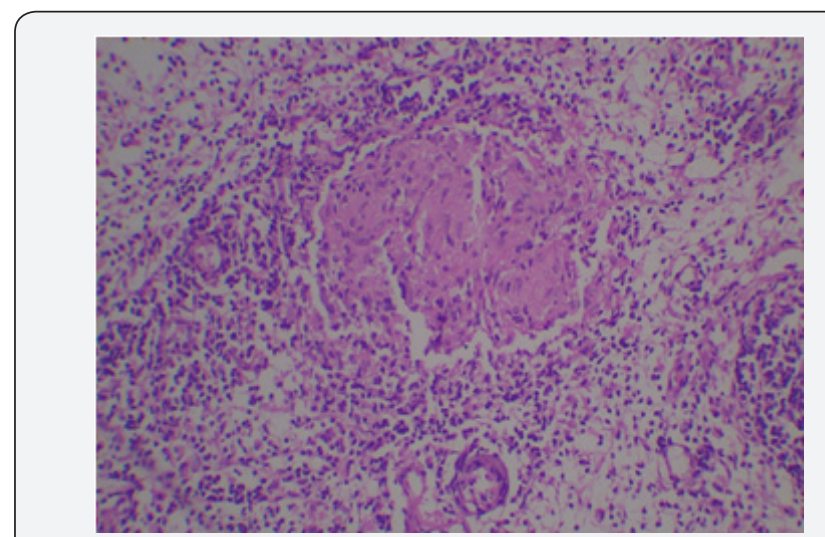

Figure 4: Epithelioid granuloma (low power image).

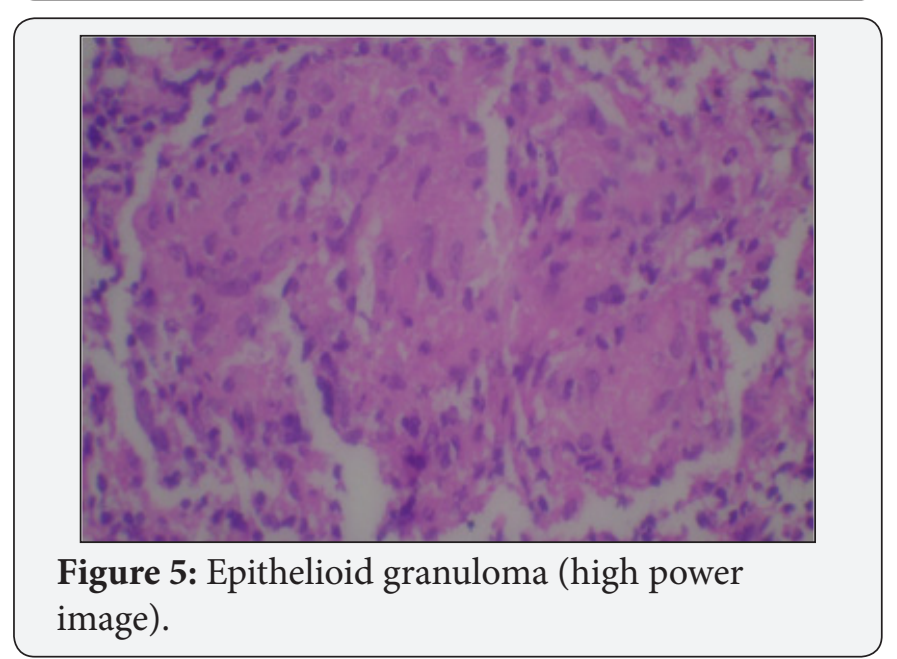

Biopsy on histopathology showed tissue lined by stratified squamous epithelium with subepithelial tissue showing edema with moderate mixed inflammation predominantly lymphocytes, plasma cells and polymorphs. Few discrete granulomas devoid of caseous necrosis and composed of epitheloid like histiocytes, few granuloma within germinal Centre of lymphoid follicles. Serum calcium level was $11.2 \mathrm{mg} / \mathrm{dl}$. Serum ACE level was 68 microgram/Ltr and Vitamin D level was 140ng/ml. Tuberculosis,

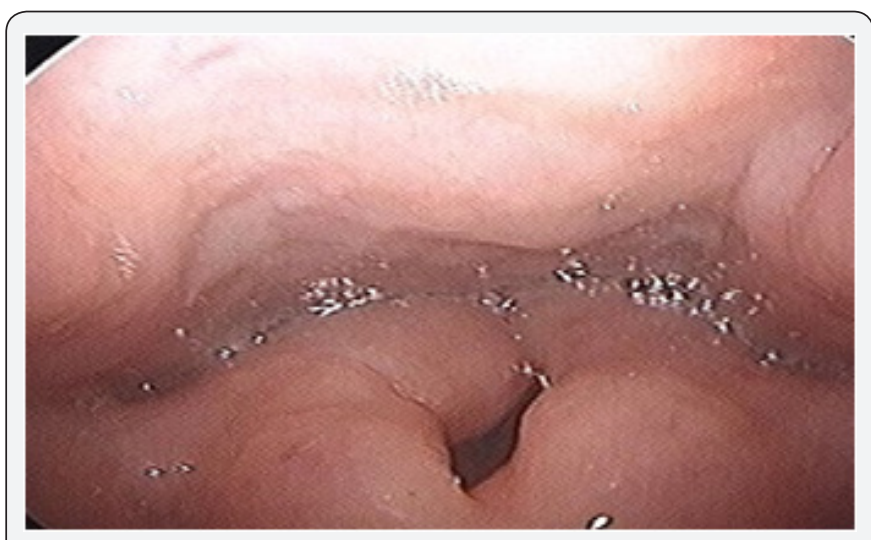

Figure 3: Endoscopic picture showing edematous aryepiglottic.

amyloidosis, and fungal infections were ruled out. Diagnosis of laryngeal sarcoidosis was made on the basis of clinical, radiological and histopathological findings. Patient was put on oral and inhalational steroids. Patient showed subjective and hematological improvement, in the form of improvement of voice, and sleeping habits. Within 2 weeks of starting treatment, Although there was no significant improvement in endoscopy picture. Improvement may also be due to partial resection of uvula. Patient is in regular followup (Figures $4 \& 5$ ).

\section{Discussion}

The Joint statement of American oracic Society (ATS)/European Respiratory Society (ERS)/World Association for Sarcoidosis and other Granulomatous Diseases (WASOG) defines sarcoidosis as a multisystem disorder of unknown cause(s) [7]. Laryngeal sarcoidosis is an underdiagnosed disease, whether for lack of specific detecting tests, turning the diagnosis into an exclusion one, or for the diversity of criteria to be analysed, so that the diagnostic suspicion can be confirmed [8]. Laryngeal disease presents with hoarseness, dyspnoea, dysphagia, chronic cough, obstructive sleep apnoea, and airway obstruction, which could progress to upper airway obstruction and emergency cricothyrotomy.

In laryngeal disease, the supraglottis region, mostly the epiglottis, is typically involved, followed by the arytenoids, aryepiglottic folds, and false vocal folds [9]. This major impairment of the supraglottis probably occurs due to the big amount of lymphatic vases in this area, which are stretchered by replacing the architecture by sarcoid deposits or subcutaneous foci of the disease [10]. In our case patient presented with change in voice, snoring and frequent arousal from sleep. Diagnostic nasal endoscopy was normal in our patient but she was having oedematous epiglottis, aryepiglottic fold, arytenoid and flase vocal cord. Our patient was also having oedema of uvula also, contrary to other studies. For a sarcoidosis diagnosis, three criteria must be met: compatible clinical-radiological findings, histological sample represented by non-necrotizing granulomas and exclusion of other granulomatoses or diseases having similar findings [11]. 
In our patient clinical-radiological finding gave us suspicion of tuberculosis, amyloidosis, fungal infection or sarcoidosis. Histopathological examination from biopsy from uvula was suggestive of granulomatous disease, ZN staining and PAS staining were negative. Tuberculosis, amyloidosis and fungal infection were ruled out. Granulomas were noncaseating composed of epitheloid like histiocytes, occasional multinucleate foreign body and langhan's giant cells. Treatment regimen includes systemic steroids, intralesional steroids for well localised lesions, laser resection, surgical excision, low dose radiation and tracheostomy. Recent literature has suggested an improvement with use of inhaled steroid and Clofazimine [12]. We started oral steroid for the patient. Patient is subjectively improved, and is in regular followup.

\section{Conclusion}

Sarcoidosis is a multisystem disorder, which rarely involves larynx as primary organ. It should be kept in mind as differential diagnosis. As if diagnosed, main management is steroid.

\section{References}

1. Ma Y, Gal A, Koss MN (2007) The pathology of pulmonary sarcoidosis: update. Semin Diagn Pathol 24(3): 150-161.

2. Ungprasert P, Carmona EM, Utz JP, Ryu JH, Crowson CS, et al. (2016) Epidemiology of Sarcoidosis 19462013: A PopulationBased Study. Mayo Clin Proc 91(2): 183188.

3. Gupta SK (2002) Epidemiology of sarcoidosis In Proceedings of the symposium. VP Chest Institute, Delhi, India.
4. Oliver SJ, Kikuchi T, Krueger JG, Kaplan G (2002) Thalidomide induces granuloma differentiation in sarcoid skin lesions associated with disease improvement. Clin Immunol 102(3): 225-236.

5. Hsu RM, Connors AF, Tomashefski JF (1996) Histologic, microbiologic, and clinical correlates of the diagnosis of sarcoidosis by transbronchial biopsy. Arch Pathol Lab Med 120(4): 364-368.

6. Rossman MD, Thompson B, Frederick M (2003) HLA-DRB1 1101: a significant risk factor for sarcoidosis in blacks and whites. Am J Hum Genet 73(4): 720-735.

7. (1999) Statement on Sarcoidosis: Joint statement of the American oracic Society (ATS), the European Respiratory Society (ERS) and the World Association of Sarcoidosis and other Granulomatous Disorders (WASOG) adopted by the ATS Board of Directors and by the ERS Executive Committee. Am J Respir Crit Care Med 160(2): 736-755.

8. Schwartzbauer HR, Tami TA (2003) Ear, nose and throat manifestations of sarcoidosis. Otolaryngol Clin North Am 36(4): 673-684.

9. Duchemann B, Lavolé A, Naccache JM, Nunes H, Benzakin S, et al. (2014) Laryngeal sarcoidosis: a case-control study. Sarcoidosis Vasc Diffuse Lung Dis 31(3):227-234.

10.Hernández PE, Casas AA, Massana EF (2003) Sarcoidosis Laríngea Aislada. Acta Otorrinolaringol Esp 54(2): 117-120.

11. Bruno TM, Luciano RN, Osíris OC, José ESP, Jose ES (2011) Laryngeal sarcoidosis: Literature review. Intl Arch Otorhinolaryngol 15(3): 359364 .

12. Vijay AR, Karthikeyan K, Jayawardena S, Muhammed UR, Rashmikant D, et al. (2005) Persistent hoarseness of voice in a sarcoid patient: A clue to laryngeal sarcoidosis; a potential cause of upper airway obstruction. Chest 128(4): 465S.

\section{Your next submission with Juniper Publishers will reach you the below assets}

- Quality Editorial service

- Swift Peer Review

- Reprints availability

- E-prints Service

- Manuscript Podcast for convenient understanding

- Global attainment for your research

- Manuscript accessibility in different formats ( Pdf, E-pub, Full Text, Audio)

- Unceasing customer service

Track the below URL for one-step submission https://juniperpublishers.com/online-submission.php 